\title{
Metoidioplasty: techniques and outcomes
}

\author{
Miroslav L. Djordjevic, Borko Stojanovic, Marta Bizic \\ Belgrade Centre for Genitourinary Reconstructive Surgery, School of Medicine, Belgrade, Serbia \\ Contributions: (I) Conception and design: ML Djordjevic; (II) Administrative support: B Stojanovic, M Bizic; (III) Provision of study materials or \\ patients: All authors; (IV) Collection and assembly of data: B Stojanovic, M Bizic; (V) Data analysis and interpretation: All authors; (VI) Manuscript \\ writing: All authors; (VII) Final approval of manuscript: All authors. \\ Correspondence to: Miroslav L. Djordjevic, MD, PhD. Professor of Urology/Surgery, Department of Urology, School of Medicine, University of \\ Belgrade, Tirsova 10, 11000 Belgrade, Serbia. Email: djordjevic@uromiros.com.
}

\begin{abstract}
Phalloplasty represents the latest step in female-to-male transitioning and still remains a great challenge for transgender surgeons. Since we have two options in this transitioning-metoidioplasty and total phalloplasty - the transgender surgeon has to fully inform the individual about all aspects such as surgical steps, outcomes, advantages and disadvantages, possible complications, and expectations. Total phalloplasty with the creation of a neophallus of a similar volume to that in genetic males, is a complex and multi-staged procedure. Many different tissues (i.e., flaps) can be used, and the ideal procedure is still not established. In contrast to the above complexities involved in total phalloplasty, metoidioplasty presents a simple and one-stage procedure for the creation of a neophallus from a hormonally enlarged clitoris. This technique is very promising for individuals who desire gender-affirmation surgery without having to undergo the difficult and multistage creation of a male-sized neophallus. Also, this technique prevents scarring to the extragenital region, making the final results more acceptable for transgender individuals. Our goal is to objectively present the techniques for metoidioplasty and to define their value based on postoperative results.
\end{abstract}

Keywords: Clitoris; female transgender; metoidioplasty; gender-affirming surgery; outcomes

Submitted Nov 25, 2018. Accepted for publication Jun 12, 2019.

doi: $10.21037 /$ tau.2019.06.12

View this article at: http://dx.doi.org/10.21037/tau.2019.06.12

\section{Introduction}

Gender-affirming surgery presents the latest development in genital transition for individuals with gender dysphoria. The World Professional Association for Transgender Health (WPATH) proposed guidelines for the treatment of transgender people. The most recent Version 8 of WPATH standards of care offers more flexible options for this treatment and defines all criteria for male-tofemale and female-to-male transgenders $(1,2)$. According to these standards, individuals are required to provide two letters of recommendation from board certified mental health providers, who should confirm gender identity and recommend further hormonal therapy according to the reallife test and "adjusting the body to the mind". Preoperative consultation with transgender surgeons with a description of desired outcomes and possible complications should be done to prevent postoperative disappointment.

Surgical transition in trans men includes bilateral mastectomy, removal of internal genital organs (uterus, ovaries, and fallopian tubes), vaginectomy, and phalloplasty. There are two options for the creation of male genitalia: total phalloplasty and metoidioplasty. Total phalloplasty presents one of the most demanding tasks in genital reconstructive surgery, as it requires the creation of a neophallus from extragenital tissue large enough to enable insertion of a penile prosthesis, penetration during sexual intercourse, and voiding in the standing position $(3,4)$. Different techniques have been described for both neophallic and neourethra reconstruction. The most common reconstruction is radial free forearm flap (RFFF) phalloplasty with simultaneous urethral reconstruction with the "tube within a tube" technique $(3,4)$. The musculocutaneous latissimus dorsi (MLD) flap is an alternative option for neophallic 
reconstruction that can meet the aesthetic and functional requirements of a transgender patient, with a hidden scar in the donor area (5).

Metoidioplasty is considered to be a very good variant of phalloplasty for female-to-male transgenders who desire an aesthetically acceptable neophallus, voiding while standing, and preservation of erogenous sensation (6). The main advantage of metoidioplasty is that it is a one-stage procedure which provides voiding while standing. Since the technique was first introduced by Durfee and Rowland, several definitive modifications have been made to the use of a hormonally enlarged clitoris for penile substitution in transmen, with the aim of better outcomes. The innovation of scrotoplasty joins both labia majora and the insertion of testicular implants, while urethral lengthening has also provided further benefits $(7,8)$. In this review, we detail and evaluate all available techniques of metoidioplasty and report the postoperative results. Our paper was approved by the Ethical Committee of the Belgrade Center for Genitourinary Reconstructive Surgery (No. 7/2018).

\section{Procedures}

Metoidioplasty presents one of the procedures for femaleto-male gender-affirming surgery. It can be performed separately or as a part of one-stage surgery that includes hysterectomy with oophorectomy and vaginectomy, urethral lengthening, scrotoplasty with insertion of testicular implants, and reconstruction of the neophallic skin (9). Based on recent literature, three different techniques are described: simple, ring, and Belgrade metoidioplasty.

\section{Simple metoidioplasty}

Simple metoidioplasty is performed on a good-sized clitoris, which is enlarged by preoperative use of testosterone. The procedure includes a subcoronal skin incision followed by degloving and transection of clitoral suspensory ligaments. The urethral plate is dissected ventrally and divided with additional correcting of the chordee. The remaining clitoral skin with the labia minora and majora is used for a clitoral body covering, giving a bulky appearance of the clitoris. The bottom of the levator muscle is also dissected and sutured in special fashion for better support of the enlarged clitoris. With this technique, the native urethral opening remains in place for possible urethral lengthening in the future. This may create possible problems with skin closure at the new scrotum part and present issues of maintenance of the normal urine outflow. A urinary catheter is used for urine drainage and to prevent leakage over the surrounding reconstructed skin. The complication rate occurs in less than $5 \%$ of cases and mainly consists of malunion or malrotation of the closing skin. Another consideration is related to vaginal removal or preservation (10). One of the main disadvantages is voiding while sitting, and an additional stage with urethral lengthening should be performed for complete patient satisfaction. Despite its limitations, this technique provides a complication-free gender-confirmation surgery with acceptable cost and fast and safe recovery (11).

Hage reported a few modifications of simple metoidioplasty based on urethroplasty (12). In this procedure, a neourethra is formed by combining the urethral plate and labia minora flap. The short plate is proximally divided at the level of the female urethral orifice. Urethral plate dissection is run proximally to distally, compromising its vascularization and leading to a high complication rate. The authors reported that 2.6 procedures were necessary to achieve optimal results in this type of surgery. Simultaneously, Perovic et al. reported good results of simple metoidioplasty in 22 patients with a complication rate of $23 \%$, mainly related to urethral reconstruction (13).

\section{Ring metoidioplasty}

This technique is similar to simple metoidioplasty but with a difference in dissection of the chordee and division of the suspensory ligaments. All of the additional procedures are included with the aim to lengthen and straighten the clitoris. Another difference is the extension of the urethral plate. With the ring technique, a special dorsal urethral ring flap is harvested from introital vaginal mucosa distally from the hymen. The ring flap is attached to the underlying clitoral bodies allowing its tubularization without pressure. The defect from the donor flap area is closed by 5-0 running resorbable suture. Compared to single metoidioplasty, one of the main improvements is the creation of a ventral urethral plate that is closed with the long vaginal flap for final urethral lengthening (14). The clitoral body is covered with the remaining labial skin creating a small neophallus.

Complications include urethral fistula (10-26\%) and stricture (3-5\%). Despite the fact that ring metoidioplasty is a one-stage procedure, the complication rate is high and demands further revisions. In almost $30 \%$ of individuals, urethral complications are a problem with voiding while standing being the main postoperative issue. Also, 
scrotoplasty with testicle implants is always done as a separate procedure, but with good outcome in the majority of cases (11).

\section{Belgrade metoidioplasty}

Belgrade metoidioplasty is based on the repair of the most severe forms of hypospadias, and minimizes the complication rate with one-stage repair $(13,15)$. The original approach has been modified several times in a continued improvement of the appearance of the newly created male genitalia and the facilitation of functional voiding while standing $(7,16)$. This technique, based on the similarity between the penile and clitoral anatomy, supports the conception of the clitoris as, in many respects, a smaller version of the penis, with the notable difference of urethral development (17). Advanced urethroplasty allowing voiding while standing is possible by using combined oral mucosa grafts and some of well-vascularized genital flaps (clitoral skin, labia minora). This way, a new urethra is created with the meatus at the top of the glans. An additional advantage is the creation of a new scrotum at the same stage with the insertion of silicone implants creating a completely normal male appearance of the genitalia in one stage. Our one-stage approach was first published in 2009, and improvements have been made on this procedure up to the present day (18).

Current metoidioplasty is based on the similarity of the clitoral and penile anatomy. The clitoris consists of two curved corpora cavernosa, a small glans with a dorsal a neurovascular bundle, and clitoral skin. Ventrally, the smooth and hairless mucosal plate joins the tip of the glans and native urethral opening making a "urethral plate". This plate additionally deforms the clitoral body making a ventral curvature. Despite the fact that hormonal treatment leads to clitoral lengthening, the enlarged clitoris is shortened and curved due to attachments of the corpora cavernosa with all the surrounding structures including the suspensory and fundiform ligaments, short urethral plate, and labia minora. This presents a limiting factor for clitoral length and the creation of the neophallus with satisfactory attributes $(17,19)$.

Belgrade metoidioplasty starts with the removal of vaginal tissue by colpocleisis. All vaginal mucosa except the small part around the urethral opening is removed. This suburethral tissue will be used for urethral lengthening. The space of the removed vaginal tissue is approximated and closed giving a male appearance of the perineum. Clitoral degloving starts around the urethral plate and includes total division of all clitoral, suspensory, and fundiform ligaments
(Figure $1 A, B)$. The ventral urethral plate is dissected and divided at the middle part enabling additional clitoral length. Urethral reconstruction is separated at the bulbar and neophallic part. The bulbar part of urethroplasty is completed by using periurethral tissue and the proximal part of the divided urethral plate. It is very important to cover this part of the neourethra with clitoral bulbs and surrounding vascularized tissue to prevent postoperative fistula formation. Additional urethral lengthening is achieved by combining oral mucosa graft and genital skin flaps (7-10). The appropriate size of the buccal mucosa graft is harvested and defatted. This procedure is safe and simple giving the possibility to always create enough graft material for reconstruction. Otherwise, oral mucosa is considered to be the best material for urethral reconstruction $(15,20)$. The graft is sutured to the corpora cavernosa in the gap created after division of the short urethral plate. This way, a new urethral plate is made. Urethroplasty is completed by using either a dorsal clitoral or labial skin flap. A labia minora flap combined with a buccal mucosa graft has been reported as the best option, resulting in a less than $7 \%$ complication rate (7). Either a skin or labial flap is joined with a buccal mucosa graft over a 12-14-French catheter to form the neourethra (Figure 1C,D). It is mandatory to cover all suture lines with the aim of preventing postoperative urethral complications. In cases with a well-developed urethral plate, urethral lengthening can be performed by simple tubularization of a wide plate. The election of this procedure relies on the excellent width and extreme mobility of the urethral plate to enable tubularization urethroplasty without affecting neophallic length (Figure 2). Reconstruction of the penile body is completed by using the remaining labial and clitoral skin. It is very important to create a well-defined penoscrotal angle. Scrotoplasty is done by joining both labia majora. Silicone implants are inserted either through the midline or using separate incisions above the labia (Figure 3). Postoperative use of a vacuum pump is necessary to prevent retraction of the neophallus, starting three weeks after surgery.

\section{Outcomes}

The Belgrade one-stage metoidioplasty is a successful variant of the procedure with satisfactory outcomes according to postoperative evaluation. Urethral reconstruction based on graft/flap technique achieved good outcome with voiding while standing and with minimal complications. Results in clitoral lengthening confirm 

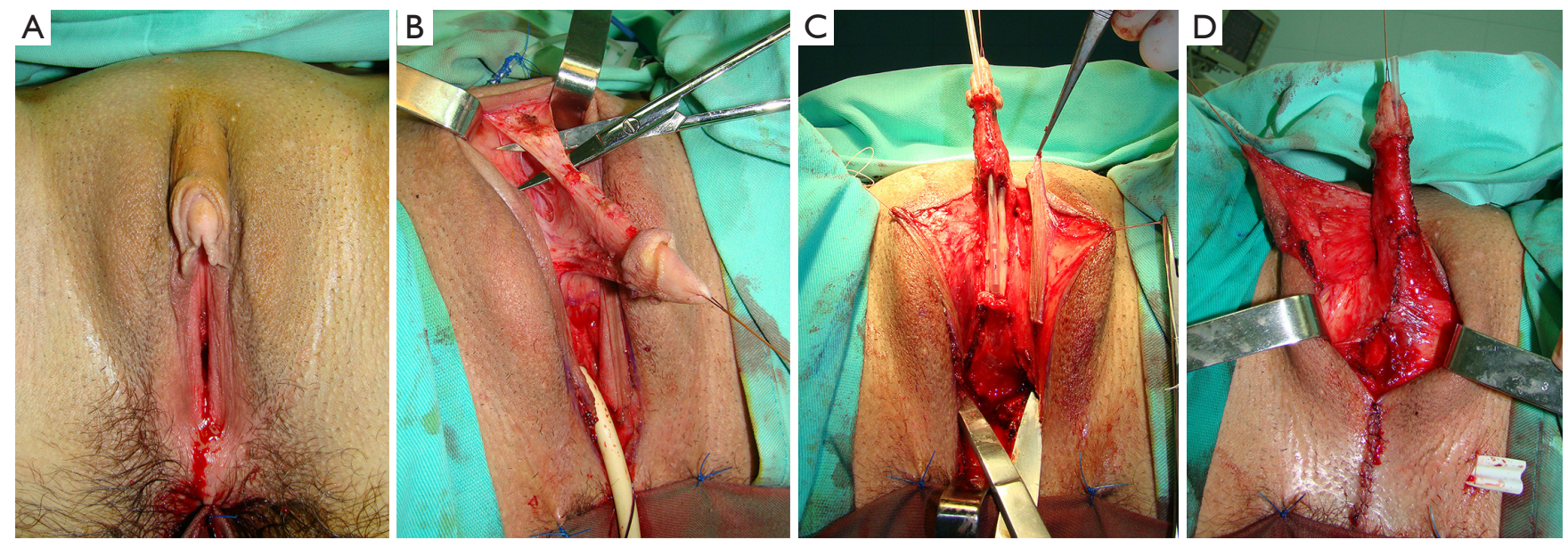

Figure 1 Belgrade metoidioplasty technique. (A) Preoperative appearance. Clitoris is hormonally enlarged. (B) Clitoral ligaments are completely divided up to the bone attachment enabling maximal lengthening of the clitoris. (C) The short urethral plate is divided, and the gap between the two parts is filled with buccal mucosa graft. A fasciocutaneous flap is harvested from the left labia minora, to be joined with the buccal mucosa graft. (D) A neourethra is formed by combining the vascularized genital flaps with the buccal mucosa graft. All suture lines are covered with well-vascularized tissue.
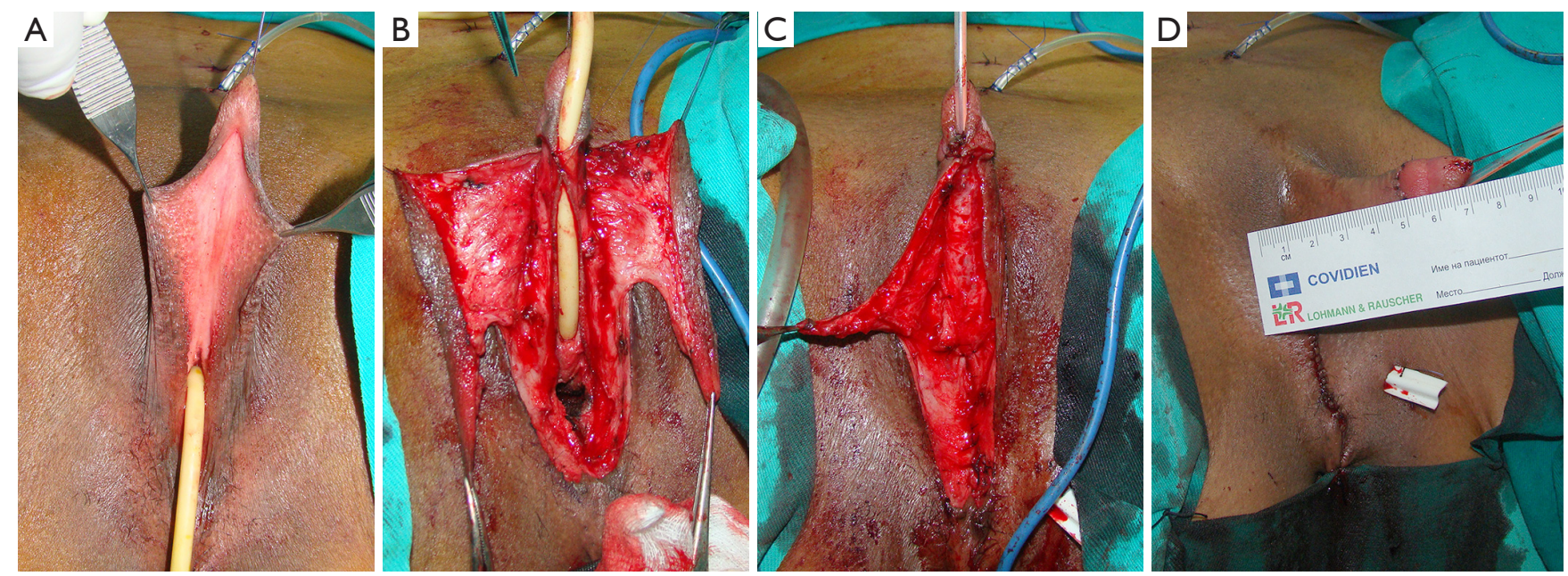

Figure 2 A case with a well-developed urethral plate (A). The urethral plate is dissected and mobilized maximally enabling easy tubularization without tension (B). Urethroplasty is complete and the neourethra is covered with surrounding tissue to prevent postoperative fistula (C). A good length of the neophallus is achieved (D).

the importance of the technique based on postoperative reports describing excellent sensation, erection, and good psychosexual features. Although the volume of the neophallus is not enough for full penetrative sexual intercourse, additional phalloplasty is always possible.

Surgical complications can be divided into minor and major categories. Minor complications are usually managed conservatively and include postoperative hematomas, local skin infections, partial necrosis, urinary infections, and some voiding problems (dribble, spraying, etc.). Major complications include urethral strictures, urethral fistulas, and problems with testicle implants (displacement, rejection). According to literature data, urethral fistula and stricture are reported in $7-15 \%$ and $2-3 \%$ of cases, respectively. Revision surgery includes excision of fistula with appropriate covering or stricture repair either by direct 


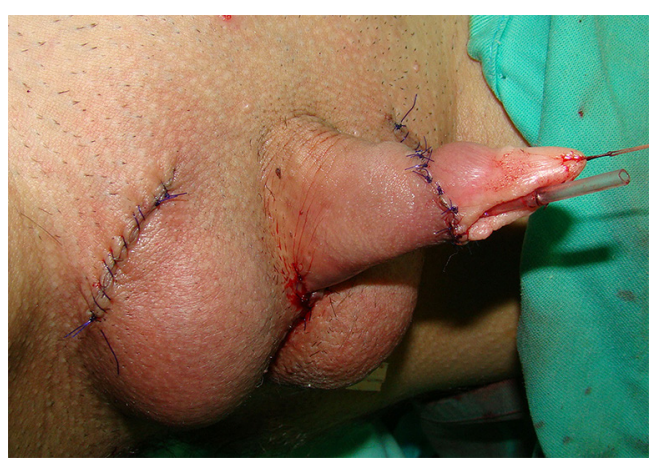

Figure 3 Appearance after metoidioplasty. Two testicle implants are inserted into the scrotum created from the joined labia majora.

anastomosis or urethral augmentation. Repair of testicular complications includes repositioning or replacement of the implants (7-9).

\section{Personal experience}

In a 15-year period [2004-2018], 593 female-to-male individuals with the mean age of 31 years (range, 1862 years) underwent one-stage Belgrade metoidioplasty. Hysterectomy and bilateral salpingo-oophorectomy were performed simultaneously in 162 patients. Urethral reconstruction with buccal mucosa graft combined with fasciocutaneous clitoral or labial flap was performed in 57 and 536 cases, respectively. Neophallic length ranged from 4-10 cm (mean $5.7 \mathrm{~cm}$ ). Erectile function without difficulties related to sexual arousal, masturbation, or orgasm was reported in all patients. According to selfreports and evaluation by a psychologist, the majority were pleased with the appearance of their new male genitalia (541 "completely satisfied" and 52 "somewhat satisfied").

Minor urethral complications, such as dribbling and spraying, occurred in $16 \%$ and resolved spontaneously without any surgical revision. Total length of the newly created urethra was measured during the surgery and ranged from $7.1-13.4 \mathrm{~cm}$ (mean $9.2 \mathrm{~cm}$ ). Urethral fistula in 48 and stricture in 10 patients were successfully repaired by minor surgical revision. Other complications such as rejection (8 patients) or testicular implant displacement (23 patients) required additional surgical correction.

\section{Summary}

Genital-affirming surgery in female-to-male transgenders is usually a multistage procedure with the main goal of creating male-like genitalia, voiding while standing, satisfactory sexual function, and good aesthetic appearance. Metoidioplasty presents a good option for creating a male genitalia by straightening and lengthening a hormonally enlarged clitoris. Additional procedures such as ligament removal, urethral lengthening, and scrotoplasty should be incorporated in any of the metoidioplasties with the goal to achieve acceptable postoperative results. Simple or ring metoidioplasty should be reserved for individuals who request neophalloplasty without the possibility of voiding in the standing position. Belgrade one-stage metoidioplasty includes simultaneous removal of internal and external female genitalia and the creation of a neophallus from the enlarged clitoris. Urethral lengthening and scrotoplasty are additional improvements, making this procedure a method of choice for genital-confirming surgery in femaleto-male transsexuals who desire a male-like appearance of their genitals, without undergoing complex and multistage procedures. The main disadvantage of metoidioplasty is that the length of the neophallus is usually inadequate for penetrative sexual intercourse. Finally, some parts of the Belgrade technique, like the dissection of clitoral entities and genital reconstruction, are difficult and should be reserved for only experienced surgeons.

\section{Acknowledgments}

Funding: This work is supported by the Ministry of Science and Technical Development, Republic of Serbia, Project No. 175048.

\section{Footnote}

Conflicts of Interest: The authors have no conflicts of interest to declare.

Ethical Statement: The authors are accountable for all aspects of the work in ensuring that questions related to the accuracy or integrity of any part of the work are appropriately investigated and resolved.

\section{References}

1. Dhejne C, Öberg K, Arver S, et al. An analysis of all applications for sex reassignment surgery in Sweden, 19602010: prevalence, incidence, and regrets. Arch Sex Behav 2014;43:1535-45. 
2. The World Professional Association for Transgender Health. Standards of Care for the Health of Transsexual, Transgender, and Gender Nonconforming People. 7th Version. 2011. Available online: https://www.wpath.org/

3. Monstrey SJ, Ceulemans P, Hoebeke P. Sex Reassignment Surgery in the Female-to-Male Transsexual. Semin Plast Surg 2011;25:229-44.

4. Morrison SD, Perez MG, Carter CK, et al. Pre- and Post-Operative Care With Associated Intra-Operative Techniques for Phalloplasty In Female-to-Male Patients. Urol Nurs 2015;35:134-8.

5. Djordjevic ML, Bencic M, Kojovic V, et al.

Musculocutaneous latissimus dorsi flap for phalloplasty in female to male gender affirmation surgery. World J Urol 2019;37:631-7.

6. Lebovic GS, Laub DR. Metoidioplasty. In: Ehrlich RM, Alter GJ. editors. Reconstructive and plastic surgery of the external genitalia. Philadelphia: WB Saunders Co., 1999:355-60.

7. Djordjevic ML, Bizic MR. Comparison of two different methods for urethral lengthening in female to male (metoidioplasty) surgery. J Sex Med 2013;10:1431-8.

8. Djordjevic ML, Bizic M, Stanojevic D, et al. Urethral Lengthening in metoidioplasty (female-to-male sex reassignment surgery) by combined buccal mucosa graft and labia minora flap. Urology 2009;74:349-53.

9. Djordjevic ML. Novel surgical techniques in female to male gender confirming surgery. Transl Androl Urol 2018;7:628-38.

10. Stojanovic B, Bizic M, Bencic M, et al. One-Stage GenderConfirmation Surgery as a Viable Surgical Procedure for Female-to-Male Transsexuals. J Sex Med 2017;14:741-6.

11. Bowers ML, Stojanovic B, Bizic M. Female-to-Male

Cite this article as: Djordjevic ML, Stojanovic B, Bizic M. Metoidioplasty: techniques and outcomes. Transl Androl Urol 2019;8(3):248-253. doi: 10.21037/tau.2019.06.12
Gender Affirmation Metoidioplasty. In: Salgado CJ, Monstrey SJ, Djordjevic ML. edsitor. Gender Affirmation: Medical and Surgical Perspectives. New York: Thieme Medical Publishers Inc., 2017:109-18.

12. Hage JJ, van Turnhout AA. Long-term outcome of metaidoioplasty in 70 female-to-male transsexuals. Ann Plast Surg 2006;57:312-6.

13. Perovic SV, Djordjevic ML. Metoidioplasty: a variant of phalloplasty in female transsexuals. BJU Int 2003;92:981-5.

14. Takamatsu A, Harashina T. Labial ring flap: a new flap for metaidoioplasty in female-to-male transsexuals. J Plast Reconstr Aesthet Surg 2009;62:318-25.

15. Djordjevic ML, Majstorovic M, Stanojevic D, et al. Combined buccal mucosa graft and dorsal penile skin flap for repair of severe hypospadias. Urology 2008;71:821-5.

16. Djordjevic ML, Stojanovic B. Metoidioplasty. In: Tran TA, Panthaki ZJ, Hoballah JJ, et al. editors. Operative dictations in plastic and reconstructive surgery. Cham, Switzerland: Springer International Publishing AG, 2017:573-7.

17. Stojanovic B, Djordjevic ML. Anatomy of the clitoris and its impact on neophalloplasty (metoidioplasty) in female transgenders. Clin Anat 2015;28:368-75.

18. Djordjevic ML, Stanojevic D, Bizic M, et al. Metoidioplasty as a single stage sex reassignment surgery in female transsexuals: Belgrade experience. J Sex Med 2009;6:1306-13.

19. Vukadinovic V, Stojanovic B, Majstorovic M, et al. The role of clitoral anatomy in female to male sex reassignment surgery. ScientificWorldJournal 2014;2014:437378.

20. Markiewicz MR, Lukose MA, Margarone JE 3rd, et al. The oral mucosa graft: a systematic review. J Urol 2007;178:387-94. 